\title{
Role of the Various Functionaries in Regular Surveillance
}

\author{
Mr. Rajesh Kumar
}

\section{INTROUCTION}

The cases that have been detected and recorded need to be compiled and transmitted to the next level on a regular basis. This should be done on a fixed date from each type of reporting unit. The day of the week for reports to reach District surveillance office from CHC, Medical colleges, Sentinel Private Practitioners (SPPs) Private Hospitals etc should be fixed by the district surveillance officer in each district. All reporting centers will provide zero reporting if no cases were detected.

1. The MO of PHC will report weekly statistics on Monday to CHC by telephone. Hard copy of Form A and Form L will also be sent by PHC to CHC once weekly. The computer /Pharmacist at the CHC will compile statistics from all PHCs along with CHC data and transmit the same every Tuesday to District Surveillance Officer through Dial up Computer network in both Form A and Form L.

2. Health worker as and when he detects additional cases during routine field visits, will add to the compiled report from $\mathrm{CHC}$ in the week of reporting. However this information may be available at PHC fortnightly when ANMs come to PHC and no alteration in this frequency is included.

3. The SPP from rural area will provide regular reports to MO PHC in form A. Weekly reports will reach every Monday to CHC. If no cases are detected, zero reports will be sent by all SPPs. The mode of transmission will be in any of the following methods.

1. E-mail

2. Letter

3. Fax

4. Telephone

5. Direct Courier

4. Medical Colleges, District Hospitals, Railway Hospitals and SPPs from urban areas will report in Form A and Form L (if there are accredited laboratories) to District Surveillance officer at weekly intervals.

Remember to report any unusual clustering of cases or any health event causing deaths in a short span of time. Use telephone, fax, email, special messenger, police wireless - any method to report immediately.

Verbal report to be followed by a written case based form If there are no cases in that week / month, do not forget to write 'zero' in the relevant row.

The designation of the person responsible for data compilation and transmission at each level is identified below:

1. PHC Pharmacist

2. CHC Computer / Pharmacists

3. SPPs MO

4. District Hospital Computer / Pharmacists

5. Medical Colleges Statistical Officer

6 Laboratory MO in charge / Laboratory Technician

The quality of the data filled up by the health staff need to be checked by a senior staff and only then transmitted. For all forms, the original has to be sent to the higher level while copy is to be maintained at the reporting unit from where it originated.

\section{THE COMMUNITY INFORMANTS}

People responsible.

Public Sector Private sector.

Rural Urban Rural Urban Teachers, AWWs, Panchayat members, Ward SHG leaders, Health club / Youth members. club / Farmer's club leaders etc.

The conditions that they would be able to identify would be syndrome of diarrhoea, jaundice, fever and unusual events leading to death or hospitalization. 
Role of the various functionaries in regular surveillance

People responsible

\section{THE MPWs and the HEALTH ASSISTANTS}

Public Sector Private sector

Rural Urban MPWs (M \& F), HA (M \& F) Urban link workers NGO peripheral workers.

The conditions that they would be able to identify would be syndrome of diarrhoea, jaundice and fever, unusual events leading to death or hospitalization, syndrome of cough, and syndrome of AFP

THE PHARMACISTS (PHC / CHC / Hospitals)

People responsible

Public Sector Private sector

Rural Urban Rural Urban Pharmacists of the PHCs, Pharmacists in the Pharmacists of private clinics, private $\mathrm{CHCs}$ and Hospitals urban dispensaries or Corporation Hospitals, hospitals and nursing homes.

People responsible

$$
\text { IV. THE MO - PHC / CHC / Private dispensaries. }
$$

Public Sector Private sector

Rural Urban Rural Urban MO of PHC / CHC MO in Dispensary Private practitioners in dispensaries The diseases that they would be able to identify would be diarrhoeal diseases, jaundice, suspected malaria, suspected typhoid, measles, suspected dengue, suspected JE, and TB.

\section{THE DISTRICT RRT (Rapid Response Team)}

People responsible

Public Sector Private sector

Rural Urban Rural Urban

District RRT Corporation RRT Not Applicable

The diseases that they would be able to identify would be diarrhoeal diseases, jaundice, suspected malaria, suspected typhoid, measles, suspected dengue, suspected JE, and TB.

People responsible

VI. THE DISTRICT SURVEILLANCE OFFICER

Public Sector Private sector

Rural Urban Rural Urban

DSO MHO Not Applicable

\section{THE DISTRICT SURVEILLANCE CELL}

People responsible

Public Sector Private sector

Rural Urban Rural Urban DSO, DHO, DTO, DMO, MHO, TB Officer, Malaria Representatives of the IMA, NGOs.

DIO, Representatives of the officer, Immunization District RRT, others involved in officer, Representatives public health prg. of the Corporation. RRT, others involved in public health prg.

People responsible

VIII. MO - HOSPITALS

Public Sector Private sector

Rural Urban Rural Urban

MOs in the Department of MO in the Department of MO in the Department of Medicine, Medicine, Pediatrics, Medicine, Pediatrics, Pediatrics, Infectious diseases and Casualty Infectious diseases and Infectious diseases and of the Private / NGO / Medical College Casualty of the District Casualty of the Municipal/ Hospitals.

Hospital. Corporation / Medical College Hospital.

The diseases that they would be able to identify would be diarrhoeal diseases, jaundice, suspected malaria, suspected typhoid, measles, suspected dengue, suspected JE, and suspected TB.

\section{THE STATISTICAL ASSISTANT - DISTRICT}

This is basically the person responsible for collating all the data at the Block / District or the Corporation Health Office. His/her activities would include

- Receiving all the data from the reporting units (CHCs, District Hospital, Private practitioners, Private institutions, Labs, Urban dispensaries etc.) The data may be received in paper/electronic format.

- Entering the data into the computer. 
- Checking the validity of the data reported. This will be done electronically and the software will have the inbuilt checks.

- Once the data is entered and checked, then the reports may be generated. These reports will be generated weekly for diseases of outbreak potential and monthly for the other communicable diseases. For non communicable diseases, the report will be generated as and when the special survey is conducted in the field.

- Once the reports are generated, they will be submitted to the District Surveillance Officer / Municipal Corporation Health Officer.

- After the analysis by the concerned officer, they will then prepare a report summarizing the analysis and submit it to the State Surveillance officer.

\section{THE LAB TECHNICIAN}

People responsible

Public Sector Private sector

Rural Urban Rural Urban

Lab technicians at the CHC Lab technicians in the Lab technicians / lab in-charge from or the Lab in charge at the urban dispensary or the accredited and identified labs District Hospital / Public lab in-charge at the Health Lab. Municipal / Corporation/Medical College Hospital The diseases that they would be able to identify would be TB, Malaria and Typhoid at CHC level, Hepatitis A, B etc, malaria, typhoid, dengue, suspected JE, TB and HIV at district level onwards.

People responsible

XI.

THE STATE SURVEILLANCE CELL

Public Sector Private sector

Rural Urban Rural Urban

Not applicable State Surveillance officer, Representatives of the IMA, NGOs.

DHS, Jt Dir - PH, Jt. Dir -

TB, Malaria, FW, DME.

XII.

ROLE OF THE VARIOUS FUNCTIONARIES IN REGULAR SURVEILLANCE

The cases that have been detected and recorded need to be compiled and transmitted to the next level on a regular basis. This should be done on a fixed date from each type of reporting unit. The day of the week for reports to reach District surveillance office from $\mathrm{CHC}$, Medical colleges, SPPs, Private Hospitals etc should be fixed by the district surveillance officer in each district. All reporting centers will provide zero reporting if no cases were detected.

The laboratory report and the clinical report are in the same forms forwarded to the DSO.

However they will be considered as independent reports.

XIII. METHOD OF PASSIVE SURVEILLANCE FROM PHC/CHC

1. The MO of PHC will report weekly statistics on Monday to CHC by E-mail. Hard copy and Soft copy of Form A and Form L will also be sent by PHC to CHC once weekly. The computer /Pharmacist at the CHC will compile statistics from all PHCs along with CHC data and transmit the same every Tuesday to District Surveillance Officer through Dial up Computer network in both Form A and Form L.

2. Health worker as when he detects additional cases during routine field visits this will be added to the compiled report from $\mathrm{CHC}$ in the week of reporting. However this information may be available at PHC fortnightly when ANMs come to PHC and no alteration in this frequency is included.

3. The Sentinel Private Practitioner from rural area will provide regular reports to MO PHC in form A. Weekly reports will reach every Monday to CHC. If no cases are detected zero reports will be sent by all SPPs. The mode of transmission will be in any of the following methods.

- E-mail

- Fax

- Telephone

4. Medical Colleges, District Hospitals, Railway Hospitals and SPPs from urban areas will report in Form A and Form L (if there are accredited laboratories) to District Surveillance officer at weekly intervals. Remember to report any unusual clustering of cases or any health event causing deaths in a short span of time. Use telephone, fax, email, special messenger, police wireless - any method to report immediately.

Verbal report to be followed by a written case based form If there are no cases in that week / month, do not forget to write 'zero' in the relevant row.

The designation of the person responsible for data compilation and transmission at each level is identified below:

1. PHC Pharmacist 
2. CHC Computer / Pharmacists

3. SPPs MO

4. District Hospital Computer / Pharmacists

5. Medical Colleges Statistical Officer

6 Laboratory MO in charge / Laboratory Technician

The quality of the data filled up by the health staff need to be checked by a senior staff and only then transmitted. For all forms, the original has to be sent to the higher level while a copy to be maintained at the reporting unit from where it originated.

\section{METHOD OF PASSIVE SURVEILLANCE BY PRIVATE HOSPITALS}

The Laboratory reports flow independent of the clinical reports in separate forms this situation and there is no linkage with clinical cases.

\section{XV. $\quad$ FORMATS FOR REPORTING:}

The passive surveillance by the reporting units will be transmitted to the District Surveillance Officer once a week since most diseases with epidemic potential has a short incubation period.

Since IDSP is primarily designed as action oriented programme. The formats have been designed to bring in information on the action taken from the reporting units as well as the frequency of diseases particularly from the public health systems participating in the programme

The formats for the private practitioners and Sentinel hospitals participating in the programme have been designed to make it feasible for SPPs to report diseases with minimum effort and has been simplified to include only the most essential summary data. The action taken will not be included from SPPs since this responsibility rests with the public health system.

The participating laboratories will have a reporting format which allow them to provide weekly summary reports of confirmed cases of diseases in the laboratories participating in IDSP.

Considering the complexity of linking clinical and laboratory records during passive reporting. It was felt that these remain unlinked for the purpose of surveillance and only feed back from laboratories be case based so that this will allow the clinician to manage cases more effectively in the participating reporting units.

\section{XVI. $\quad$ LABORATORY NETWORK AT DISTRICT LEVEL:}

From To Functionary Frequency* Source / Forms Method of transmission Sentinel Private District Nodal lab Weekly From Lab register to In clustering of cases or suspected labs Surveillance technician Form L epidemic situation. Any available officer method of communication may be used. Telephone, fax, courier Medical College District Nodal lab Weekly From the lab registers in Electronic communication with Laboratory surveillance technicians Form L DSO officer Telephone, Fax, E-mail, network District Public District Officer in charge Weekly Summary format to be Through District Computer network Health Laboratory Surveillance of District Lab completed at District so that feed back from DPHL is Officer public health laboratory. quickly available for case Case based reports for management at the reporting units Quality assurance tests District Public All reporting Officer in charge As early as Case based reports for Through District Computer network Health Laboratory units of District Lab possible case management so that feed back from DPHL is quickly available for case management at the reporting units.

\section{DISTRICT SURVEILLANCE UNIT:}

The district surveillance unit will collate the information received electronically from CHC, Medical colleges, District hospitals, and by courier or by mail from SPPs and other laboratories on a weekly basis. This will be analyzed and forwarded to State surveillance officer at weekly intervals.

District Reporting Units DSO Dial up Summary quality control These will be summary reports send at Surveillance Connectivity reports monthly frequency officer Feed back reports District State DSO Real time From Forms A, B, C to Form D All compile non case based information Surveillance Surveillance connectivity will be available to the state officer officer from district to surveillance officer from rural / urban, state envisaged Government and SPPs in real time connectivity.

District Reporting Units DSO Dial up Case based reports for case The reports will be made available Surveillance Connectivity management. As soon as through the network and made Officer laboratory tests are ready available through dial up connectivity to reporting units. 